Richards KL, Xu R, Gazina EV, Petrou S. Heat opens axon initial segment sodium channels. A febrile seizure mechanism? Ann Neurol Aug 2009;66:219-226). (Respond: Dr Petrou, Howard Florey Institute, University of Melbourne, Parkville, Victoria 3010 Australia. Email: spetrou@unimelb.edu.au).

COMMENT. The mechanism of febrile seizures is dependent on several factors, but especially height of body temperature and an individual's febrile convulsive threshold. In addition to genetic susceptibility and cytokines, the neurotropic properties of certain viruses, age and level of immaturity, and water and electrolyte balance are contributing factors. (Millichap JG. Brain Dev 2009; Dube CM et al. Brain Dev 2009;31:366-371). The above study provides further explanations for the febrile seizure mecanism at a molecular level, and specifically the effect of body temperature on brain sodium channels.

\title{
ANTIPYRETICS AND FEBRILE SEIZURE RECURRENCE
}

The efficacy of antipyretic agents in prevention of febrile seizures was examined in a randomized, placebo-controlled, double-blind trial at various hospitals in Finland. A total of 231 children who experienced their first febrile seizure, Jan 1, 1997-Dec 31, 2003, were observed for 2 years. Febrile episodes were treated first with rectal diclofenac or placebo. After 8 hours, treatment was continued with oral ibuprofen, acetaminophen, or placebo. Of 851 febrile episodes, $89(10 \%)$ were associated with a febrile seizure. Febrile seizures occurred in 54 (23.4\%) of the 231 children. Recurrence rates were not significantly different in the antipyretic and placebo groups: $23.4 \%$ (46 of 197) in those treated with antipyretic, and $23.5 \%$ ( 8 of 34 ) in those receiving placebo $(\mathrm{P}=0.99)$. Fever was significantly higher during episodes with seizure vs those without seizure $(39.7 \mathrm{C}$ vs $38.9 \mathrm{C}, \mathrm{P}<0.001)$, independent of the medication. Antipyretic agents were ineffective in the prevention of febrile seizure recurrence. All the antipyretics failed to lower the body temperature in children with fever that was associated with febrile seizure recurrence, but they lowered the temperature in episodes not leading to a febrile seizure. Children with recurrences had received extra antipyretic agents more frequently than those without recurrences. (Strengell T, Uhari M, Tarkka R, et al. Antipyretic agents for preventing recurrences of febrile seizures. Arch Pediatr Adolesc Med Sept 2009;163:799-804). (Respond: Heikki Rantala MD, PhD, Department of Pediatrics, University of Oulu, PO Box 5000, Oulu 90014, Finland. E-mail: heikki.rantala@oulu.fi).

COMMENT. The ineffectiveness of commonly prescribed antipyretics in the prevention of recurrence of febrile seizures, as demonstrated in this controlled study, is in agreement with the majority of previous randomized trials. Antipyretics may be useful only in improving the general wellbeing of the febrile child. In patients with a prior complex febrile seizure, to prevent recurrence, many pediatric neurologists recommend a combination of antipyretic with diazepam, administered orally at first sign of fever.

While antipyretics failed to prevent or control temperature elevation that resulted in seizure recurrence, they were effective in lowering temperature in episodes unassociated with seizure. The principal aim in therapy is the prevention of an elevation of temperature above the threshold level at which a seizure has previously occurred. Commonly employed antipyretics, while facilitating heat dissipation by increased peripheral blood flow and 
sweating, have no effect on heat production and temperature elevation. They begin to act when the fever has reached its highest point (Goodman and Gilman, 1955). In laboratory studies of antipyretic agents, aspirin and acetaminophen failed, whereas barbiturates were effective in retarding temperature elevation induced by radiotherm diathermy in animals. High doses of salicylates that cause hyperventilation and respiratory alkalosis lowered the threshold convulsive temperature and exacerbated the hyperthermia-induced seizure. (Millichap JG et al. Neurology 1960;10:575). The prevention of febrile seizures by anticonvulsant medications may be as much antipyretic as anticonvulsant effect. Future research in the development of more effective antipyretics should target heat production more than heat dissipation. The authors from Finland comment on the inhibition of different prostaglandins by antipyretics and the potential for different effects on seizure recurrence.

\section{FEBRILE SEIZURES AND COGNITIVE OUTCOME}

The association between febrile seizures and cognitive function in young adulthood was examined in a population-based study of Danish conscripts at Aarhus University Hospital, Denmark. Men with a history of epilepsy were excluded. Analysis of health-care databases found that $2.8 \%$ of 18,276 eligible conscripts had a record of hospitalization for febrile seizures. Prevalence of IQ scores in the bottom quartile $(<37)$ was $25.3 \%$ and $27.6 \%$ for men with and without febrile seizures, respectively. Low IQ scores were slightly more prevalent in men born premature $(30 \%)$, small for gestational age $(32 \%)$, mother $<20$ years $(36 \%)$, or parity $>3(33 \%)$. Adjusted prevalence ratios for having a group IQ score in the bottom quartile was 1.09 for men with febrile seizures and 1.08 for those without.. The prevalence ratios according to age at febrile seizure onset were 1.38 for 3 months to $<1 \mathrm{yr}$; 0.98 for 1 to 2 years; and 1.14 for 3 to 5 years. Except for men whose febrile seizures occurred before age 1 year, there was little evidence of low cognitive function associated with a history of febrile seizures. (Noergaard M, Ehrenstein V, Mahon BE, Nielsen GL, Rothman KJ, Sorensen HT. Febrile seizures and cognitive function in young adult life: a prevalence study in Danish conscripts. J Pediatr Sept 2009;155:404-409). (Respond: Mette Noergaard MD PhD, Dept Clinical Epidemiology, Aarthus University Hospital, Sdr Skovve 15, DK-9000 Aalborg, Denmark. E-mail: m.noergaard@rn.dk).

COMMENT. Decreased cognitive function in young adults with a history of febrile seizures before age $1 \mathrm{yr}$ is previously unreported. In another Danish study, children with a febrile seizure early $(<1 \mathrm{yr})$ or late $(>3 \mathrm{yr})$ had a higher rate of epilepsy compared to children with onset between 1 and 3 years (Vestergaard $M$ et al. Am J Epidemiol 2007;165:911-918). Abnormal MRIs in 11.4\% of children with first simple febrile seizures, reported in a NY-Presbyterian Hospital study, was also an unexpected finding, given the presumed benign nature of the febrile seizure. (Hesdorffer DC et al. Epilepsia 2008;49:765771; Ped Neur Briefs June 2008;22:47-48). MRI is not usually recommended in children with simple febrile seizures, in accordance with AAP guidelines.

\section{BULGING FONTANELLE AND NEED FOR LUMBAR PUNCTURE}

Etiologies of bulging fontanelle and fever and clinical evidence for lumbar puncture were determined from medical records of 153 infants treated at Assaf Harofeh Medical 